\title{
RUSTIFICAÇÃO DE PLANTAS DE Eucalyptus dunnii Maiden E A RELAÇÃO ENTRE AS CONCENTRAÇÕES DE CARBOIDRATOS SOLÚVEIS TOTAIS E DE PROLINA FOLIAR E A TOLERÂNCIA AO FRIO ${ }^{1}$
}

\author{
Mireli Moura Pitz Floriani², Cristiano André Steffens ${ }^{3}$ e Djalma Miler Chaves²
}

\begin{abstract}
RESUMO - O objetivo desta pesquisa foi avaliar o efeito da aclimatação sobre a tolerância ao frio de mudas de Eucalyptus dunnii Maiden (clone K-1007) e a relação entre a tolerância ao frio e as concentrações foliares de carboidratos solúveis totais e de prolina. O delineamento experimental utilizado foi de blocos ao acaso com quatro repetições. Os tratamentos consistiram de diferentes períodos de aclimatação (0, 7, 21 e 42 dias de exposição às plantas a temperaturas diurnas de $5^{\circ} \mathrm{C}$ e noturnas de $1^{\circ} \mathrm{C}$ ). Após cada período de aclimatação, as mudas foram submetidas a quatro gradientes de temperatura negativas $\left(-2{ }^{\circ} \mathrm{C},-4{ }^{\circ} \mathrm{C},-6{ }^{\circ} \mathrm{C}\right.$ e $\left.-8{ }^{\circ} \mathrm{C}\right)$, por $3 \mathrm{~h}$ cada gradiente. Após cada período de aclimatação, foram avaliadas as concentrações foliares de carboidratos solúveis totais e prolina. Após cada gradiente de temperatura negativa, foram coletadas amostras foliares para a avaliação da temperatura letal de $50 \%\left(\mathrm{TL}_{50}\right)$. Os dados foram submetidos à análise de regressão linear e teste de correlação de Pearson. As mudas de E. dunnii apresentaram aumento nos teores de carboidratos solúveis até 28 dias de aclimatação; após esse período, as concentrações permaneceram estáveis. Observou-se correlação negativa entre a temperatura letal de $50 \%\left(\mathrm{TL}_{50}\right)$ e a concentração de carboidratos solúveis totais no tecido foliar. Dessa forma, observou-se aumento na tolerância ao frio com o aumento dos teores de carboidratos solúveis no período de aclimatação de até 28 dias.
\end{abstract}

Palavras-chave: Temperatura letal de 50\% $\left(\mathrm{TL}_{50}\right)$, Aclimatação e Temperatura negativa.

\section{RUSTIFICATION OF Eucalyptus dunnii Maiden PLANTS AND THE RELATIONSHIP OF THE TOTAL SOLUBLE CARBOHYDRATES AND PROLINE CONTENTS IN THE LEAVES TO COLD TOLERANCE}

\begin{abstract}
The aim of this work was to evaluate the effect of acclimatization on the cold tolerance of Eucalyptus dunnii Maiden (clone K-1007) and the relationship of the cold tolerance to the total soluble carbohydrates and proline contents in the leaves. The experimental design utilized was randomized blocks with four repetitions. The treatments were made up of different acclimatization periods $(0,7,21$ and 42 days of plant exposure to the temperatures of $5^{\circ} \mathrm{C}$ daily and $1^{\circ} \mathrm{C}$ at night.). After each acclimatization period, the seedlings were submitted to four sub-zero temperatures $\left(-2^{\circ} \mathrm{C},-4^{\circ} \mathrm{C},-6^{\circ} \mathrm{C}\right.$ and $\left.-8^{\circ} \mathrm{C}\right)$ for three hours each temperature. After each acclimatization period the concentrations of total soluble carbohydrates and proline in the leaves was evaluated. After each sub-zero temperature, leaf samples were collected for evaluation of the lethal temperature $50 \%\left(L T_{50}\right)$. The data were submitted to linear regression analysis and Person's correlation test. The E.dunnii seedlings showed an increase in the content of total soluble carbohydrates up to 28 days of acclimatization, with stabilization occurring after this period. It was observed that there was a negative correlation between the temperature of lethal temperature $50 \%\left(L T_{50}\right)$ and the concentration of total soluble carbohydrates in the leaftissues, showing a relation of cold tolerance increase to the increase of contents of total soluble carbohydrates
\end{abstract}

Keywords: Lethal temperature of 50\% ( $\left.L T_{50}\right)$, Acclimatization and Subzero temperature.

\footnotetext{
${ }^{1}$ Recebido em 21.11.2008 e aceito para publicação em 25.08.2010.

${ }^{2}$ Unidade de Negocio, KLABIN PAPEIS, Brasil. E-mail: <mmpitz@klabin.com.br>.

${ }^{3}$ Universidade do Estado de Santa Catarina, UDESC, Brasil. E-mail: <steffens@cav.udesc.br>.
} 


\section{INTRODUÇÃO}

Entre os fatores mais limitantes da expansão dos plantios de Eucalyptus spp. na região do Planalto Catarinense, destaca-se a ocorrência de geadas. As temperaturas quando próximas ou abaixo de $0{ }^{\circ} \mathrm{C}$ ocasionam danos em espécies do gênero Eucalyptus, que vão desde a perda da área foliar até a morte das plantas (FILHO e SANTOS, 2005).

Muitas plantas apresentam a capacidade de desenvolver mecanismos específicos para a sobrevivência em ambientes que apresentam períodos episódicos e prolongados de congelamento (LARCHER, 2000). Este autor citou também que os mecanismos de evasão e proteção para evitar a formação de gelo nos tecidos definem a capacidade de tolerância e de sobrevivência de uma planta sob clima frio e que a resistência ou tolerância ao frio pode ser característica genética que as plantas possuem, bem como pode ser característica induzida por modificações ambientais que antecedem as primeiras geadas.

Efeitos específicos do agente estressante geralmente têm alvo bem definido no interior da planta, e consequentemente, em cada caso os sintomas induzidos são altamente específicos, e mecanismos específicos de resistência ou tolerância envolvem todos os níveis funcionais, muitas vezes induzidos por ação genética diferenciada, como na síntese de proteínas de estresse e outras enzimas especiais (LARCHER, 2000).

A resistência ou sensibilidade ao estresse por temperaturas abaixo de $0{ }^{\circ} \mathrm{C}$ depende da espécie, do genótipo e da idade de desenvolvimento da planta (PALVA et al., 2002). Para Filho e Santos (2005), E. dunnii é indicado para plantios em regiões com temperaturas mínimas absolutas de até $-5{ }^{\circ} \mathrm{C}$ sob condições de aclimatação prévia, mediante a gradual redução da temperatura na estação fria, suportando nessas condições até 22 geadas anuais. A maioria das plantas resistentes ou tolerantes ao frio pode ter sua tolerância aumentada através da indução ambiental, em consequência da exposição a baixas temperaturas, acima do ponto de congelamento (LARCHER, 2000). Segundo Levitt (1980) e Nilsen e Orcutt (1996), a indução pode ocorrer quando a planta é exposta a baixas temperaturas, geralmente entre 0 e $10^{\circ} \mathrm{C}$, período esse chamado de aclimatação ou de rustificação.

Revista Árvore, Viçosa-MG, v.35, n.1, p.21-29, 2011
A geada é fator ambiental determinante na adaptação das espécies de Eucalyptus na Região Sul do Brasil, sendo um dos principais fatores a serem considerados para o êxito dos plantios florestais (HIGA et al., 1997; HIGA e HIGA, 2000). Na região do Planalto Serrano de Santa Catarina, devido à ocorrência de geadas, devem-se escolher genótipos com características que confiram resistência ou tolerância a baixas temperaturas. Segundo Larcher (2000), algumas dessas características podem estar associadas às concentrações de carboidratos solúveis totais e prolina no tecido vegetal. Em amoras silvestres, a tolerância ao frio é acompanhada pelo acúmulo de açúcares solúveis e aminoácidos, como a prolina (PALONEN e JUNTTILA, 1999). Considera-se que esses solutos protegem as membranas celulares e as enzimas contra dano irreversível causado pelas geadas (MORAGA et al., 2006), sendo a diminuição da pressão osmótica em plantas aclimatadas predominantemente o resultado do aumento na concentração de carboidratos solúveis (VALENTINI et al., 1990).

Jacobsen et al. (2007) utilizaram a determinação da temperatura letal $\left(\mathrm{TL}_{50}\right)$ para avaliar a tolerância ao frio e identificaram diferentes mecanismos de resistência ao frio e capacidade de aclimatação em cultivares de quinoa (Chenopodium quinoa Willd.), oriundas de diferentes condições agroecológicas do Sul do Peru. Os referidos autores observaram diferenças significativas entre os cultivares, períodos de aclimatação e valores de temperatura letal $\left(\mathrm{TL}_{50}\right)$, além de diferentes resultados no conteúdo de carboidratos solúveis totais e de prolina. Monteros e Jacobsen (1999) já haviam demonstrado, em quinoa, que o aumento no nível de carboidratos solúveis totais implica maior tolerância ao frio. Assim, esses autores afirmaram que as diferenças significativas entre a concentração de carboidratos solúveis totais, temperatura de resfriamento e temperatura letal $\mathrm{TL}_{50}$ podem ser utilizados como indicadores de tolerância ao frio.

O objetivo desta pesquisa foi avaliar a resistência à baixa temperatura através da temperatura letal 50\% $\left(\mathrm{TL}_{50}\right)$ em mudas de Eucalyptus dunnii submetidas a diferentes níveis de aclimatação, bem como verificar a existência de correlação entre os teores de carboidratos solúveis totais e prolina com a tolerância ao frio.

\section{MATERIAL E MÉTODOS}

Este trabalho foi conduzido no Laboratório de Fisiologia Vegetal do Centro de Ciências Agroveterinárias da Universidade do Estado de Santa Catarina - UDESC, 
no município de Lages. Foram utilizadas 48 mudas de Eucalyptus dunnii Maiden (clone K-1007) com cinco meses de idade, procedentes do viveiro florestal da empresa Klabin, localizado no Município de Telêmaco Borba, PR.

O experimento foi realizado conforme o delineamento de blocos ao acaso, sendo utilizados quatro repetições de cada tratamento com três plantas. Os tratamentos utilizados foram quatro períodos de aclimatação $(0,7,21$ e 42 dias de exposição das mudas às temperaturas diurnas de $5{ }^{\circ} \mathrm{C}$ e noturnas de $1^{\circ} \mathrm{C}$ ) e quatro gradientes de temperatura abaixo de zero $\left(-2,-4,-6\right.$ e $\left.-8{ }^{\circ} \mathrm{C}\right)$. Os dados foram submetidos à análise de variância e, em seguida, à análise de regressão linear (períodos (dias) de aclimatação e gradientes de temperatura) e análise de correlação por Pearson (teor foliar de carboidratos solúveis totais e temperatura letal de 50\%).

Os tratamentos utilizados foram quatro períodos de aclimatação 0, 7, 21 e 42 dias de exposição em temperaturas diurnas de $5{ }^{\circ} \mathrm{C}$ e noturnas de $1{ }^{\circ} \mathrm{C}$, sob fotoperíodo controlado (12/12 h luz/escuro). Ao final de cada nível de aclimatação, as mudas foram submetidas a quatro gradientes de temperatura abaixo de zero $\left(-2,-4,-6\right.$ e $\left.-8{ }^{\circ} \mathrm{C}\right)$, por $3 \mathrm{~h}$ cada gradiente. No entanto, antes de as mudas serem submetidas à aclimatação intensa, elas foram mantidas em fotoperíodo controlado (12/12 h luz/escuro) com temperaturas diurnas de $20^{\circ} \mathrm{C}$ e noturnas de $12^{\circ} \mathrm{C}$, durante seis dias para pré-aclimatação nas câmaras de crescimento. Em seguida, as temperaturas foram alteradas para temperatura diurna de $15^{\circ} \mathrm{Cenoturna}$ de $9{ }^{\circ} \mathrm{C}$, durante sete dias, mantendo-se o fotoperíodo controlado (12/12 h luz/escuro).

As mudas de Eucalyptus dunnii Maiden foram obtidas através de sementes procedentes de pomar clonal, localizado em Telêmaco Borba, PR, originárias da Austrália. Foram semeadas em tubetes com volume de $90 \mathrm{~cm}^{3}$, no viveiro da empresa, onde permaneceram por três meses após a emergência, atingindo no final do terceiro mês $30 \mathrm{~cm}$ de altura. O substrato utilizado foi constituído de partes iguais de casca de arroz carbonizada e vermiculita tipo 3 e fertilizadas com 4,0 kg de Osmocote ${ }^{\circledR}(19-06-10)+1,5$ kg de Superfosfato simples + 500 g de MAP (monoamônio fosfato) +150 g de sulfato ferroso + 150 g de FTE BR 12 (Frited trace elements - micronutrientes) por metro cúbico. Em seguida, as mudas foram transplantadas para sacos plásticos com volume de $2.000 \mathrm{~cm}^{3}$, contendo o mesmo substrato utilizado na semeadura e permanecendo por mais dois meses no viveiro. No final desse período, as mudas atingiram, em média, $50 \mathrm{~cm}$ e foram transferidas para o laboratório para condução do experimento.

Osmocote ${ }^{\circledR}$ (19-06-10) é um fertilizante com tempo de liberação em torno de quatro a seis meses que, além de conter $19 \%$ de $\mathrm{N}, 06 \%$ de $\mathrm{P}_{2} \mathrm{O}_{5}$ e $10 \%$ de $\mathrm{K}_{2} \mathrm{O}$, apresenta em sua formulação 3,8\% de Ca, 1,5\% de Mg, 3,0\% de S, $0,02 \%$ de $\mathrm{B}, 0,05 \%$ de $\mathrm{Cu}, 0,5 \%$ de $\mathrm{Fe}, 0,1 \%$ de $\mathrm{Mn}$, 0,004\% de Mo e $0,05 \%$ de Zn. Pelo fato de o Osmocote permitir a disponibilidade contínua de nutrientes para as mudas, durante maior tempo, há menor possibilidade de ocorrer deficiência de nutrientes durante o período de formação das mudas, o que dispensaria aplicações parceladas de outras fontes, diminuindo, assim, os custos operacionais na formação da muda. É um fertilizante indicado tanto para produção de mudas de algumas frutíferas (MENDONÇA et al., 2004a-c) quanto ornamentais e oleráceas (BRITTON et al., 1998; PILL e BISCHOFF, 1998).

As variáveis dependentes avaliadas foram concentrações foliares de carboidratos solúveis totais e de prolina e temperatura letal de $50 \%\left(\mathrm{TL}_{50}\right)$.

\subsection{Determinação de $\mathrm{TL}_{50}$ através da Condutividade Elétrica (CE)}

A $\mathrm{TL}_{50}$ (temperatura letal em que ocorrem 50\% da mortalidade celular) foi determinada através da condutividade elétrica (CE) do tecido foliar após o fato de as plantas serem submetidas aos gradientes de temperatura abaixo de zero e uma nova medida, depois de os tecidos serem submetidos a uma temperatura de $90{ }^{\circ} \mathrm{C}$ por $4 \mathrm{~h}$. Dessa forma, para a análise da condutividade elétrica foram utilizadas 10 folhas coletadas da região mediana do quarto par de ramos, sendo retirados dois discos do limbo foliar com $11 \mathrm{~mm}$ de diâmetro com perfurador de rolha na posição mediana da folha, sem atingir a nervura principal.

Em seguida, os discos foram colocados em frascos de vidro com $30 \mathrm{~mL}$ de água deionizada, deixando-se em repouso por $24 \mathrm{~h}$ na temperatura ambiente. $\mathrm{Na}$ sequência, foi realizada a leitura da condutividade elétrica (CE inicial) com condutivímetro Mettler Toledo modelo MPC 227. Após essa leitura, a amostra foi levada à estufa previamente regulada à temperatura de $90^{\circ} \mathrm{C}$, ficando nessa condição por $4 \mathrm{~h}$. Na sequência, a amostra permaneceu em temperatura ambiente por 12 h, e após esse período foi realizada nova leitura da condutividade

Revista Árvore, Viçosa-MG, v.35, n.1, p.21-29, 2011 
elétrica (CE final). Através dos valores de CE inicial e CE final, obtém-se a temperatura letal TL através da fórmula TL = (CE final - CE inicial $) /(C E$ inicial $) \times 100$, sendo a temperatura abaixo de zero, que resulta num valor de mortalidade do tecido de $50 \%$, considerada a temperatura letal de $50 \%\left(\mathrm{TL}_{50}\right)$, conforme descrito por Flint et al. (1967).

\subsection{Determinação de carboidratos solúveis totais}

As folhas frescas coletadas para a determinação da condutividade elétrica foram congeladas em nitrogênio líquido e armazenadas a uma temperatura de $-20{ }^{\circ} \mathrm{C}$, com o objetivo de diminuit o metabolismo celular, e para a posterior análise do teor de carboidratos solúveis totais.

A extração e análise dos teores de carboidratos solúveis totais foram realizadas conforme metodologia descrita por Moraga et al. (2006), utilizando-se o método fenol sulfúrico. As folhas de cada amostra, previamente armazenadas, foram maceradas sem a nervura central com aproximadamente $25 \mathrm{~mL}$ de nitrogênio líquido em almofariz e pistilo de porcelana. Depois de maceradas, retirou-se 0,3 g de massa seca e colocada em tubo de ensaio; logo após, adicionaram-se $3 \mathrm{~mL}$ de etanol 80\%, agitando e colocando a mistura por 30 minutos em banhomaria a uma temperatura de $60^{\circ} \mathrm{C}$. Posteriormente, a amostra foi agitada manualmente por 30 segungos e depois centrifugada numa temperatura de $4{ }^{\circ} \mathrm{C}$ a $4.000 \mathrm{rpm}$, por 30 minutos. Após a centrifugação, $1 \mathrm{~mL}$ da fase líquida foi transferida para outro tubo de ensaio, adicionando-se a este $1 \mathrm{~mL}$ de clorofórmio e $1 \mathrm{~mL}$ de água deionizada, deixando a mistura em repouso durante 45 a 60 minutos e obtendo a separação de fases, compostas por pigmentos no fundo do tubo e carboidratos dissolvidos em meio aquoso na parte superior.

Em outro tubo de ensaio, pipetaram-se $200 \mathrm{~mL}$ da fase aquosa obtida, e adicionou-se 1,8 mL de água deionizada (solução 1). Dessa solução 1, retiraram-se $500 \mathrm{~mL}$ e as transferiram para outro tubo de ensaio, onde foram adicionados $500 \mathrm{~mL}$ de fenol (5\%) e 2,5 mL de ácido sulfúrico concentrado. Logo após, agitou-se em vortex e, em seguida, foi realizada a medição da absorbância da solução em espectrofotômetro, utilizando um comprimento de onda de 485 nm. Para obtenção dos valores de concentração de carboidratos solúveis totais, utilizou-se a curva de calibração y $=0,0081 \mathrm{x}$ + 0,0744 (sendo $\mathrm{y}=$ absorbância; e $\mathrm{x}=$ concentração de carboidratos; $\mathrm{R}^{2}=0,9988$ ). Essa curva de calibração foi realizada usando-se concentrações de glicose variando de zero (água destilada/deionizada) a $500 \mathrm{ml}$ de soluçãopadrão de glicose (100 mg/mL).

\subsection{Determinação de prolina}

Para determinação de prolina foi utilizado o método de Bates et al. (1973), sendo 0,25 g de massa seca de folhas maceradas em nitrogênio líquido sem a nervura principal, juntamente com $5 \mathrm{~mL}$ de ácido sulfossalicílico $3 \%$. Em seguida, a mistura foi centrifugada por 5 minutos a 3.000 rpm na temperatura ambiente, sendo depois coletado $1 \mathrm{~mL}$ de sobrenadante e transferido para um tubo de ensaio, adicionando-se $1 \mathrm{~mL}$ de ninidrina ácida e $1 \mathrm{~mL}$ de ácido acético glacial. Posteriormente, as amostras foram colocadas em banho-maria por $1 \mathrm{~h} \mathrm{a} 100^{\circ} \mathrm{C}$. Em seguida, as amostras foram resfriadas em gelo, sendo adicionados em seguida $2 \mathrm{~mL}$ de tolueno puro e agitado vigorosamente em vórtex, por 30 segundos, para separação das fases (o tolueno extrai a substância cromófora formando um complexo colorido avermelhado). Depois de a solução atingir a temperatura ambiente, aspirou-se a fase aquosa superior (cromóforo + tolueno), para leitura em espectrofotômetro a 520 nm. Para obtenção dos valores de concentração de prolina, utilizou-se a curva de calibração y = 0,0959x - 0,2147 (sendo y = absorbância; $x$ = concentração de prolina; e $\left.\mathrm{R}^{2}=0,9926\right)$. Essa curva de calibração foi realizada utilizando-se concentrações de prolina variando de zero (água destilada/deionizada) a $500 \mathrm{ml}$ de solução-padrão de prolina $(100 \mathrm{mg} / \mathrm{mL})$.

\section{RESULTADOS E DISCUSSÕES}

Os dados obtidos na pesquisa após serem submetidos à análise de variância e regressão linear demonstraram, com relação ao dano causado pelas baixas temperaturas, que houve redução no percentual de dano (mortalidade) com o aumento no período de aclimatação até 21 dias (Figura 1). Nas temperaturas de $-2{ }^{\circ} \mathrm{C},-4{ }^{\circ} \mathrm{C},-6{ }^{\circ} \mathrm{C}$ e $-8{ }^{\circ} \mathrm{C}$, as mudas que foram submetidas a períodos de zero e sete dias de aclimatação apresentaram resultados de dano (mortalidade de 50\%) muito semelhantes, em torno de 35\%, 50\%, 75\% e 80\%, respectivamente. Já as mudas submetidas a 21 dias de aclimatação a $-2{ }^{\circ} \mathrm{C}$, $-4{ }^{\circ} \mathrm{C},-6{ }^{\circ} \mathrm{C}$ e $-8{ }^{\circ} \mathrm{C}$ tiveram mortalidade menor em torno de 20\%, 25\%, 60\% e 70\%, respectivamente. Dessa forma, observou-se que o melhor período de aclimatação das mudas de E. dunnii (clone K-1007) seria de 21 dias para aumentar sua concentração de carboidratos solúveis totais, diminuindo a intensidade de dano. 


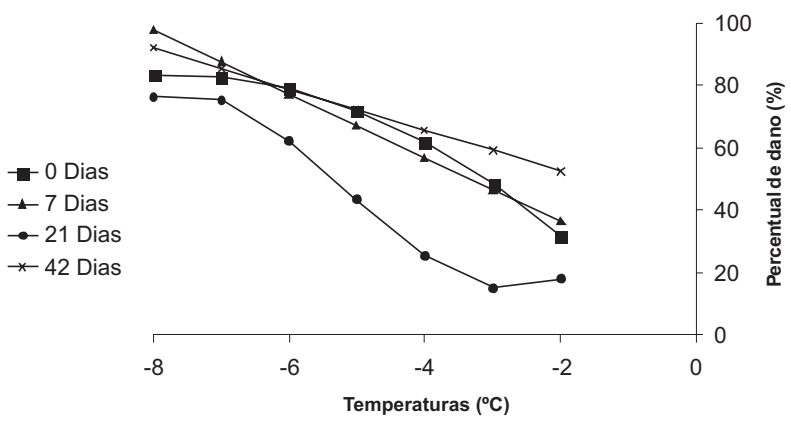

Figura 1 - Relação do percentual de dano (\%) em Eucalyptus dunnii submetidos a diferentes gradientes de temperatura abaixo de zero $\left({ }^{\circ} \mathrm{C}\right)$ e períodos de aclimatação.

$\left(\mathrm{y}_{0 \text { dias }}=-1,61 \mathrm{x}^{2}-24,63 \mathrm{x}-11,09 \mathrm{r}^{2}=0,9663\right.$;

$\mathrm{y}_{7 \mathrm{dias}}=-10,25 \mathrm{x}+15,84 \quad \mathrm{r}^{2}=0,9384$;

$y_{21 \text { dias }}=1,08 x^{3}+16,63 x^{2}+65,88 x+92,03 \quad r^{2}=1$;

$\mathrm{y}$ dias $\left.=-6,61 \mathrm{x}+39,16 \mathrm{r}^{2}=0,8090\right)$.

Figure 1 - Relation of damage percentage (\%) in Eucalyptus dunnii seedlings submitted to different gradient sub-zero temperatures $\left({ }^{\circ} \mathrm{C}\right)$ within four acclimatization periods.

$\left(y_{0_{\text {days }}}=-1.61 \times 2-24.63 x-11.09 \quad r 2=0.9663\right.$; $y_{\text {7days }}=-10.25 x+15.84 \quad r 2=0.9384$;

$y_{21 \text { days }}=1.08 \times 3+16.63 \times 2+65.88 x+92.03 r 2=1$; $\left.y_{42 \text { days }}=-6.61 x+39.16 r 2=0.8090\right)$.

Observou-se, através da análise de correlação por Pearson, que as mudas de E. dunnii apresentaram correlação significativa e negativa entre a temperatura de $\mathrm{TL}_{50}$ e a concentração de carboidratos solúveis no tecido foliar de E. dunii, com aumento nos teores de carboidratos solúveis em resposta ao aumento do período de aclimatação em até 28 dias (Figura 2). Esse resultado está de acordo com os obtidos por Shvaleva et al. (2008), que observaram em Eucalyptus globulus aumento no teor de carboidratos solúveis totais com a aclimatação das plantas. Segundo Larcher (2000), nas plantas lenhosas a aclimatação é iniciada pela exposição das plantas a temperaturas um pouco acima de $0{ }^{\circ} \mathrm{C}$ por muitos dias ou até semanas, e nesse estádio de pré-aclimatação os carboidratos e outras substâncias protetoras são acumulados na parede celular (TAIZ e ZEIGER, 2006). Ainda, esses autores citaram que, após esse período, o protoplasma está pronto para a próxima fase, quando as biomembranas e as enzimas são modificadas, de forma que as células são capazes de tolerar a perda de água em decorrência da formação de gelo. Embora nem todas as espécies sejam capazes de exibir aumento de tolerância ao frio em resposta à aclimatação (MORAGA et al., 2006), o nível mais alto é alcançado pela exposição

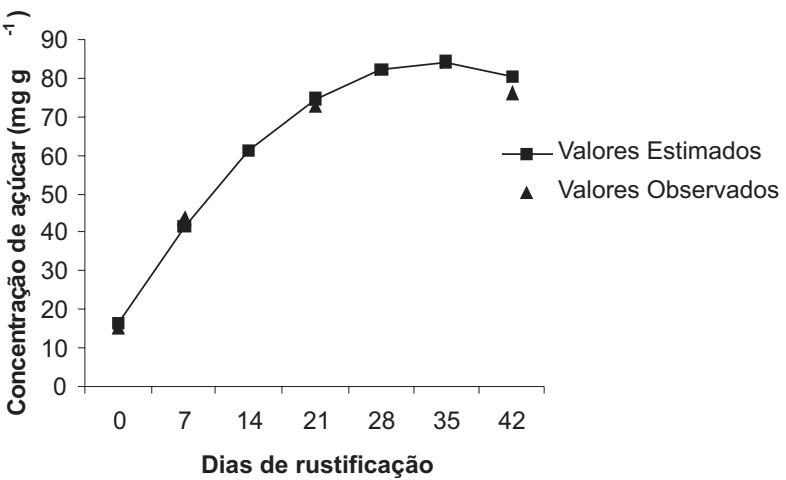

Figura 2 - Concentração foliar de carboidratos solúveis totais $\left(\mathrm{mg} . \mathrm{g}^{-1}\right)$ em Eucalyptus dunnii em resposta à aclimatação.

Figure 2 - Leaf concentration of total soluble carbohydrates (mg. $\mathrm{g}^{-1}$ ) in Eucalyptus dunnii in response to the increase in the acclimatization period.

ininterrupta das plantas a temperaturas de $0{ }^{\circ} \mathrm{C}$ a $10^{\circ} \mathrm{C}$ (LEVITT, 1980; NILSEN e ORCUTT, 1996) ou de $5^{\circ} \mathrm{C}$ a $15{ }^{\circ} \mathrm{C}$, uma vez que essa faixa de temperatura pode variar entre espécies (LARCHER, 2000).

Observando a Figura 2, constatou-se que no período de zero dia de aclimatação as concentrações foliares de carboidratos solúveis totais eram de $15 \mathrm{mg} \mathrm{g}^{-1}$, e após o período de sete dias as concentrações passaram a ser de $40 \mathrm{mg} \cdot \mathrm{g}^{-1}$, atingindo aos 21 dias teores em torno de $70 \mathrm{mg}^{-1} \mathrm{~g}^{-1}$, estabilizando os teores de carboidratos em 80 mg. $\mathrm{g}^{-1}$ num período de 28 dias de aclimatação.

Os valores de concentrações foliares de carboidratos solúveis totais variaram de $15 \mathrm{mg} \mathrm{g}^{-1}$ a $80 \mathrm{mg} \cdot \mathrm{g}^{-1}$ no período de até 28 dias de aclimatação, e observou-se que o aumento das concentrações nesse período refletiu um valor de $\mathrm{TL}_{50}$ menor, em que num período de 21 dias de aclimatação o $\mathrm{TL}_{50}$ ficou em torno de $-5,34{ }^{\circ} \mathrm{C}$ (Tabela 1), demonstrando, dessa forma, que existe relação no aumento da concentração foliar de carboidratos solúveis com maior tolerância das mudas de Eucalyptus dunnii (clone K-1007) ao frio.

Aos 42 dias de aclimatação, no entanto, surpreendentemente o valor de $\mathrm{TL}_{50}$ aumentou (Tabela 1), causando percentuais de dano de 55\%, 60\%, 75\% e $80 \%$, nas temperaturas de $-2{ }^{\circ} \mathrm{C},-4{ }^{\circ} \mathrm{C},-6{ }^{\circ} \mathrm{C}$ e $-8{ }^{\circ} \mathrm{C}$, respectivamente (Figura 1). Observou-se, ainda, redução no teor de carboidratos solúveis totais, embora não na mesma proporção (Figura 2).

Revista Árvore, Viçosa-MG, v.35, n.1, p.21-29, 2011 
Tabela 1 - Temperaturas de $\mathrm{TL}_{50}\left({ }^{\circ} \mathrm{C}\right)$ em função de diferentes períodos de aclimatação (dias de exposição das mudas de Eucalyptus dunnii a temperaturas diurnas de $5{ }^{\circ} \mathrm{C}$ e noturnas de $1{ }^{\circ} \mathrm{C}$ ).

Table 1 - Temperatures of $L T_{50}\left({ }^{\circ} \mathrm{C}\right)$ in Eucalyptus dunnii seedlings submitted to different acclimatization periods (days of exposition to daily $5^{\circ} \mathrm{C}$ and night $1{ }^{\circ} \mathrm{C}$ temperatures).

\begin{tabular}{cc}
\hline Período de Rustificação (dias) & $\mathrm{LT}_{50}\left({ }^{\circ} \mathrm{C}\right)$ \\
\hline 0 & $-2,48$ \\
7 & $-3,33$ \\
21 & $-5,34$ \\
42 & $-1,64$ \\
\hline
\end{tabular}

Levitt (1980) e Nilsen e Orcutt (1996) observaram que a indução de resistência ao frio pode ocorrer quando a planta é exposta a baixas temperaturas, geralmente entre 0 e $10^{\circ} \mathrm{C}$, período esse chamado de aclimatação ou rustificação. A resistência ao frio em mudas é determinada por mecanismos de fuga e tolerância (LARCHER 2000; NILSEN e ORCUTT,1996). O primeiro corresponde a um mecanismo em que a planta evita a formação de gelo nos seus tecidos, e o segundo permite o congelamento nos tecidos da planta, no entanto sem consequências letais (LARCHER, 2000; NILSEN e ORCUTT, 1996). Larcher (2000) afirmou que os danos causados pelo congelamento podem ser evitados por mecanismos de proteção e evasão nas células, os quais inibem ou retardam o congelamento do tecido. Um desses processos pode envolver maior conteúdo de solutos dissolvidos nas células, reduzindo o ponto de congelamento e tornando a célula mais tolerante a baixas temperaturas (JACOBSEN, 2007). Quanto às plantas que devem atravessar com sucesso um período de temperaturas abaixo do ponto de congelamento, é essencial que seu protoplasma seja tolerante ao congelamento, sendo essa condição alcançada pela elevada incorporação de fosfolipídios estáveis nas biomembranas e pela acumulação de carboidratos solúveis na parede celular (TAIZ e ZEIGER, 2006), poliois, aminoácidos, poliaminas (PALONEN e JUNTTILA, 1999) e também proteínas hidrossolúveis (LARCHER, 2000).

De acordo com os resultados da análise de correlação, houve correlações significativa e negativa entre a temperatura letal de $50 \%\left(\mathrm{TL}_{50}\right)$ e a concentração de carboidratos solúveis no tecido foliar de E. dunnii submetido aos quatro períodos de aclimatação (Figura 3).

Observa-se na Figura 3 que as mudas entram no período de aclimatação com concentrações foliares em torno de $15 \mathrm{mg}^{-1}{ }^{-1}$ e um $\mathrm{TL}_{50}$ em média de $2,5^{\circ} \mathrm{C}$,

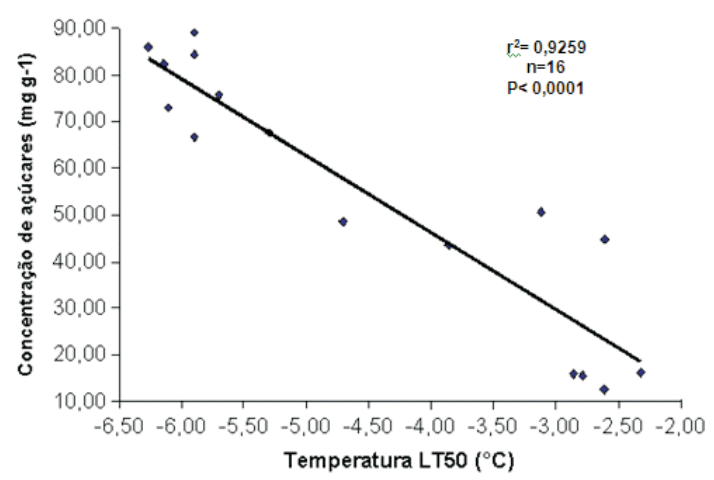

Figura 3 - Correlação entre $\mathrm{TL}_{50}\left({ }^{\circ} \mathrm{C}\right)$ e concentrações de carboidratos solúveis totais (mg. $\mathrm{g}^{-1}$ ) em Eucalyptus dunnii submetidos a quatro períodos de aclimatação.

Figure 3-Correlation between the $L T_{50}\left({ }^{\circ} \mathrm{C}\right)$ and leaf concentrations of total soluble carbohydrates $\left(\mathrm{mg} . \mathrm{g}^{-1}\right)$ in Eucalyptus dunnii submitted to four acclimatization periods.

chegando no final do período de aclimatação a $80 \mathrm{mg} \mathrm{g}^{-1}$ e um $\mathrm{TL}_{50}$ em torno de $-6^{\circ} \mathrm{C}$. Esses resultados indicam que se as mudas fossem expostas aos gradientes de temperaturas $-2{ }^{\circ} \mathrm{C},-4^{\circ} \mathrm{C},-6{ }^{\circ} \mathrm{C}$ e $-8{ }^{\circ} \mathrm{C}$, já possuindo inicialmente concentração foliar de carboidratos solúveis totais de $80 \mathrm{mg} \mathrm{g}^{-1}$, a mortalidade nas mudas seria menor, ou seja, seriam mais tolerantes ao frio. Isso corrobora, dessa forma, os resultados de Jacobsen et al. (2007), que afirmaram que o aumento no nível de carboidratos solúveis implica maior tolerância ao frio, podendo as diferenças significativas entre conteúdo de açúcares totais, temperatura de resfriamento e $\mathrm{TL}_{50}$ ser utilizadas como indicadoras de tolerância ao frio. Tinus et al. (2000) e Moraga et al. (2006) concordaram que os teores de carboidratos solúveis totais são bom indicativo da resistência a baixas temperaturas e apresentam

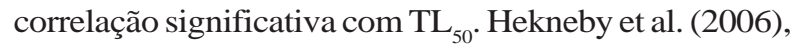
em leguminosas, também observaram que a aclimatação ao frio diminuiu o $\mathrm{TL}_{50}$ e aumentou a concentração de carboidratos solúveis totais nas folhas de todas as espécies avaliadas. Correlação negativa entre o conteúdo de carboidratos solúveis e a temperatura letal de 50\% ( $\left.\mathrm{TL}_{50}\right)$ também foi obtida em E. gunnii (LEBORGNE et al., 1995). Da mesma forma, Bravo et al. (1998) afirmaram que, em quinoa, o conteúdo foliar de carboidratos solúveis teve correlação com a temperatura de congelamento e de $\mathrm{TL}_{50}$. Em diferentes subespécies de Eucalyptus globulus foi observada correlação inversa entre o conteúdo de carboidratos solúveis totais e o TL 50 após passarem por um período de aclimatação (MORAGA et al., 2006), confirmando os resultados dos trabalhos. 
Nas análises de prolina, identificou-se nos tecidos das plantas concentração média de $48,5 \mathrm{mg} \mathrm{g}^{-1} \mathrm{MS}$, a qual não foi influenciada pelo período de aclimatação (dados não apresentados). Isso demonstra que o incremento na tolerância ao frio em E. dunnii em resposta ao aumento no período de aclimatação não possui relação com os teores foliares de prolina.

Almeida et al. (1993) avaliaram a resistência ao frio e a capacidade de aclimatação de mudas de diferentes genótipos de Eucalyptus globulus e hídridos (E.gunnii $\mathrm{X}$ globulus, E. viminalis X globulus e E. cyllocarpa $\mathrm{X}$ globulus), concluindo que o aumento na resistência em Eucalyptus pode ser relacionado com o incremento na concentração de carboidratos solúveis totais e que a concentração do teor de prolina não aumentou em resposta a aclimatação ao frio, estando de acordo com os resultados deste trabalho. No entanto, no híbrido E. cypellocarpa X globulus esses autores observaram relação entre o conteúdo foliar de prolina e a tolerância ao frio, demonstrando que essa relação depende do genótipo a ser considerado.

Segundo Gomes et al. (2002), na determinação da qualidade das mudas prontas para o plantio os parâmetros utilizados baseiam-se ou nos aspectos fenotípicos, denominados morfológicos, ou nos internos das mudas, de fisiológicos. A tolerância ao frio é um dos aspectos fisiológicos necessários para a sobrevivência de mudas no campo no Planalto Catarinense. Para Chaves et al. (2004), é possível que a análise de características ecofisiológicas de plantas, ainda no estádio juvenil, produza resultados igualmente confiáveis, em testes de campo.

Os resultados deste trabalho demonstram que a tolerância ao frio em $E$. dunnii está fortemente relacionada ao aumento nos teores foliares de carboidratos solúveis totais e não com o conteúdo foliar de prolina. Esses resultados estão de acordo com os obtidos por Jacobsen et al. (2007), em que esses autores observaram que a tolerância ao frio em cultivares de quinoa (Chenopodium quinoa Willd.), oriundos de diferentes condições agroecológicas do Sul do Peru, apresentou correlação significativa entre o conteúdo de carboidratos solúveis totais, porém o conteúdo foliar de prolina não mostrou correlação.

Os resultados do experimento sugerem que a determinação da concentração foliar de carboidratos solúveis totais em mudas de Eucalyptus dunnii pode ser característica quantitativa a ser considerada na seleção de espécies tolerantes ao frio em programas de melhoramento.

\section{CONCLUSÕES}

Os resultados permitem concluir que:

1) A exposição de plantas de Eucalyptus dunnii (clone K 1007) à aclimatação aumenta a sua tolerância ao frio até 28 dias de exposição a temperaturas diurnas de $5^{\circ} \mathrm{C}$ e noturnas de $1{ }^{\circ} \mathrm{C}$, sendo essa tolerância a baixas temperaturas fortemente relacionada à concentração foliar de carboidratos solúveis totais.

2) Em Eucalyptus dunnii (clone K 1007), o teor foliar de prolina não contribui para a tolerância ao frio.

\section{AGRADECIMENTOS}

À empresa Klabin S.A. e à Universidade do Estado de Santa Catarina, pela parceria firmada para a realização desta pesquisa.

\section{REFERÊNCIAS}

ALMEIDA, M. H.; CHAVES, M. M.; SILVA, J. C. Cold acclimation in eucalypt hybrids. Tree Physiology, n.14, p.921-932, 1993.

BATES, L. S. WALDRENR, P.; TEARE, I. D. Rapid determination of free proline for water stress studies. Plant and Soil, v.39, n.1, p.205-207, 1973.

BRAVO, L. A. et al. The role of ABA in freezing tolerance and cold acclimation in barley. Physiologia Plantarum, v.103, n.1, p.17-23, 1998.

BRITTON, W.; HOLCOMB, E. J.; BEATTIE, D. J. Selecting the optimum slow-release fertilizer of five cultivars of tissue-cultured Hosta.

HortTechnology, v.8, n.2 , p. 203-206, 1998.

CHAVES, J. H. et al. Seleção precoce de clones de eucalipto para ambientes com disponibilidade diferenciada de água no solo: relações hídricas de plantas em tubetes. Revista Árvore, v.28, n.3, p.333-341, 2004.

FLINT, H. L.; BOYCE, B. R.; BEATTIE, D. J. Index of Injury - a useful expression of freezing injury to plant tissues as determined by the electrolytic method. Canadian Journal Plant

Science, v.47, n.2, p.229-230, 1967.

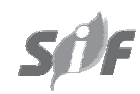

Revista Árvore, Viçosa-MG, v.35, n.1, p.21-29, 2011 
GOMES, J. M. et al. Parâmetros morfológicos na avaliação da qualidade de mudas de Eucalyptus grandis. Revista Árvore, v.26, n.6, p.655-664, 2002.

HEKNEBY, M.; ANTONÍN, M. C.; SÁNCHEZDIAS, M. Frost resistance and biochemical changes during cold acclimation in different annual legumes. Enviromental and Experimental Botany, v.55, n.3, p.305314, 2006.

HIGA, R.C.V. et al. Comportamento de vinte espécies de Eucalyptus em área de ocorrência de geadas na região sul do Brasil. In: IUFRO CONFERENCE ON SILVICULTURE AND IMPROVEMENT OF EUCALYPT, 1997, Salvador. Proceedings... Colombo: Embrapa, Centro Nacional de Pesquisa de Florestas, 1997. p.106-110.

HIGA, A. R.; HIGA, R. C. V. Indicação de espécies para reflorestamento. In: GALVÃO, A. P. M. (Ed.). Reflorestamento de propriedades rurais para fins produtivos e ambientais: um guia para ações municipais e regionais. Brasília: Embrapa Comunicação para Transferência de Tecnologia, Embrapa Florestas. p. 101-124, 2000.

JACOBSEN, S. E. et al. Frost resistance mechanisms in quinoa (Chenopodium quinoa Willd.) Europen Journal of Agronomy, v.26, n.4, p.471-475, 2007.

LARCHER, W. Ecofisiologia vegetal. São Carlos: Rima, 2000. 398p.

LEBORGNE, N. et al. Introduction of specific carbohydrates into Eucalyptus gunnii cells increases their freezing tolerance. European Journal of Biochemistry, v.229, n.3, p.710-717, 1995.

LEVITT, J. Responses of plants to environmental stresses: chilling, freezing and hight temperatures stresses. 2.ed. New York: Academic Press, 1980. p.67-344.

MENDONÇA, V. et al. Formação de mudas de maracujazeiro-doce com uso de fertilizante Osmocote e misturas alternativas de substratos. R. Ceres, v.51, n.295, p.383-390, 2004.

Revista Árvore, Viçosa-MG, v.35, n.1, p.21-29, 2011
MORAGA S. P.; ESCOBAR, R.; VALENZUELA, A. S. Resistance to freezing in three Eucalyptus globulus Labill subspecies. Electronic Journal of Biotechnology, v.9, n.3, p.310-314, 2006.

MONTEROS, C.; JACOBSEN, S. E. Resistance of quinoa (Chenopodium quinoa Willd.) to frost. In: COST 814- WORKSHOP: Alternative Cops for Sustainable Agriculture, 1999, Turku, Finland. Proceedings... Turku, Finland, 1999. p.319-325.

NILSEN, E.; ORCUTT, D. The physiology of plants under stress. New York: John Wiley \& Sons, 1996. p.704.

PALONEN, P.; JUNTTILA, O. Cold hardening of raspberry plants in vitro is enhanced by increasing sucrose in the culture medium. Physiologia Plantarum. v. 106, n. 4, p. 386-392, 1999.

PALUDZYSZYN FILHO, E.; SANTOS, P. E. T. Considerações sobre o plantio de Eucalyptus dunnii no estado do Paraná. Colombo: Embrapa, 2005. (Comunicado Técnico, 141).

PALVA, E. T. et al. Biological mechanism of low temperature stress response: Cold acclimation and development of freezing tolerance in plants.

Japan International Research Center for Agricultural Sciences, Working Report. 2002. p.9-19.

PILL, W. G.; BISCHOFF, D. J. Resin-coated, controlledrelease fertilizer as a pre plant alternative to nitrogen enrichment of stem core in soilless media containing ground stem core of kenak (Hibiscus cannabinus L.). Journal Horticultural Science and Biotechnological, v. 73, n.1, p.73-79, 1998.

SHVALEVA, A. et al. Physiological and biochemical responses to low non-freezing temperature of two Eucalyptus globulus clones differing in drought resistance. Annals of Forest Science, v.65, n.2, p.204, 2008.

TAIZ, L.; ZEIGER, E. Plant physiology. Sunderland: Sinauer Associates, 2006. 764p. 
TINUS, R.W. et al. Relationship between carbohydrate concentration an root growth potential in coniferous seedlings from three climate during cold hardening and dehardening. Three Physiology, v.20, n.16, p.1097-1104, 2000.
VALENTINI, R.G.; SCARASCIA-MUGNOZZA; KUZMINSKY E. Influence of cold hardening on water relations of three Eucalyptus species. Tree Physiology, n.6, n.1, p.1-10, 1990. 
